\title{
Using Tandem Mass Spectrometry \\ to Predict Chemical Transformations \\ of 2-Pyrimidinyloxy- $N$-Arylbenzyl Amine Derivatives in Solution
}

\author{
Hao-Yang Wang, Xiang Zhang, and Yin-Long Guo \\ Shanghai Mass Spectrometry Center, Shanghai Institute of Organic Chemistry, Chinese Academy of Sciences, \\ Shanghai, China
}

\section{Qing-Hong Tang and Long Lu}

Key Laboratory of Organofluorine Chemistry, Shanghai Institute of Organic Chemistry, Chinese Academy of Sciences, Shanghai, China

Tandem mass spectrometry is used to predict the chemical transformations of 2-pyrimidinyloxy- $N$-arylbenzyl amine derivatives. Compound 1, N-2-2-4,6- dimethoxypyrimidin-2-yloxy benzylamino phenyl benzamide was selected as a model to present our idea. The CID reactions of protonated 1 include an intramolecular $S_{N} 2$ reaction and a cyclodehydration reaction. Under in-source CID conditions, deprotonated 1 undergoes a Smiles rearrangement reaction and then dissociates to the ion at $\mathrm{m} / \mathrm{z} 349$. Theoretical computations were invoked to shed light on the reaction mechanisms of 1 by the semiempirical PM3 method. These studies of gas-phase reactions show the reactivity of some potential reaction centers in this molecule, which inspired us to explore the solution phase analogous reactions of 1. Further experiments show that 1 has two analogous reactions in acidic solution: the acid-catalyzed cyclodehydration reaction and the acid-catalyzed Smiles rearrangement reaction. Moreover, $\mathbf{1}$ undergoes the base-catalyzed Smiles rearrangement under basic conditions. The present study demonstrates that mass spectrometry can play an important role in predicting the chemical solution phase transformations of 2-pyrimidinyloxy- $\mathrm{N}$-arylbenzyl amine derivatives. (J Am Soc Mass Spectrom 2006, 17, 253-263) (c) 2006 American Society for Mass Spectrometry

$\mathrm{T}$ There is increasing interest and demand for simultaneously monitoring pesticides as well as related degradation products (DPs) in the environment, as the latter compounds can be even more toxic than the former compounds. When released into the environment, herbicides are subjected to various biotic and abiotic processes such as photolysis, oxidation, hydrolysis, and biodegradation leading to different transformation products with environmental behaviors and toxicity different from those of the parent compounds [1-5]. Chemical transformations catalyzed by acidic or basic conditions are normally found in the environment. Mass spectrometry (MS) techniques, especially methods involving tandem mass spectrometry, have been widely used in many scientific fields as detection systems and for structure elucidation. The study of fragmentation pathways is particularly useful in the

Published online January 18, 2006

Address reprint requests to Dr. Y.-L. Guo, Shanghai Mass Spectrometry Center, Shanghai Institute of Organic Chemistry, Chinese Academy of Sciences, Shanghai 200032, P.R. China. E-mail: ylguo@mail.sioc.ac.cn, also to Prof. Long Lu, Key Laboratory of Organofluorine Chemistry, Shanghai Institute of Organic Chemistry, Chinese Academy of Sciences, Shanghai 200032, P. R. China. E-mail: lulong@mail.sioc.ac.cn. characterization of analytes and the identification of specific transitions, since it permits their unequivocal assignment [6-8]. Certain analogies between mechanisms in the gas phase and in solution have been known for a long time, and sometimes it is possible to correlate the behavior of charged species formed in the gas phase and in the solution phase [9-13]. Therefore, mass spectrometry, especially tandem mass spectrometry, can also act as an important gas-phase "physical organic" tool for mechanistic studies of organic unimolecular reactions under solvent-free conditions [14]. In fact, the modern mass spectrometer has been termed as a "complete chemical laboratory" by Beynon and coworkers [15].

2-Pyrimidinyloxy- $N$-arylbenzyl amine derivatives were developed by the Shanghai Institute of Organic Chemistry. These compounds have many favorable properties, such as high herbicidal activity, a low dose rate of application, and a high degree of degradation [16]. For simplicity in discussion, compounds discussed here are assigned a numbers ( 1 to 8 ) and their structures are shown in Scheme 1. Previous mass spectrometric studies of protonated 2-pyrimidinyloxy- $N$-arylbenzyl amine derivatives revealed some interesting gas-phase rearrangement/fragmentation reactions [17-19]. In 


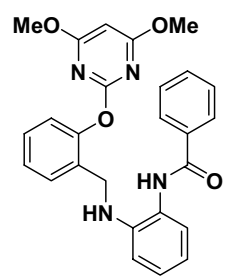

1

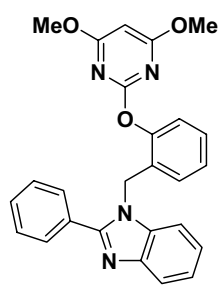

2

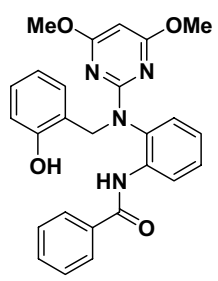

3

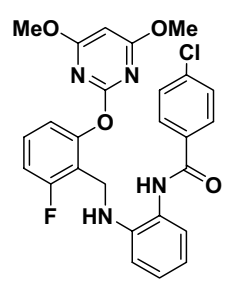

4

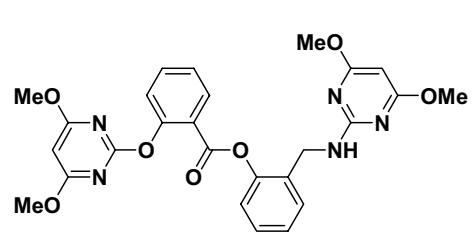

5
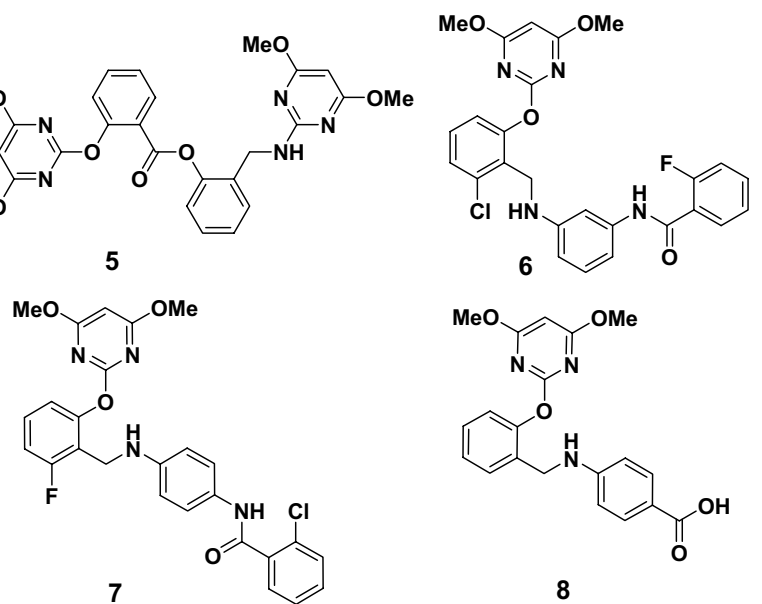

8

Scheme 1. The chemical structures of eight 2-pyrimidinyloxy- $N$-arylbenzylamine derivatives discussed in this article (Compounds 1-8).

particular, the gas-phase $S_{N} A r$ type rearrangement inspired us to investigate the acid-catalyzed Smiles rearrangement reaction of 2-pyrimidinyloxy- $\mathrm{N}$-arylbenzylamine derivatives in solution phase [20]. These results show that the gas-phase reactions of the protonated (or deprotonated) 2-pyrimidinyloxy- $\mathrm{N}$-arylbenzyl amine derivatives initiated by collision induced dissociation (CID) have similarities with the analogous solution phase reactions. Thus, we want to show whether it is possible to predict chemical transformations in solution by using tandem mass spectrometry.

Compound 1, N-2-2-4,6-dimethoxypyrimidin-2yloxy benzylamino phenyl benzamide, was selected as a model to present our idea: using tandem mass spectrometry to predict chemical transformations of this compound. First, the gas-phase reactions of protonated and deprotonated $\mathbf{1}$ and its related compounds are fully discussed. Second, some theoretical computations are carried out to support the proposed mechanisms of these gas-phase reactions. From the studies of the gas-phase reactions of $\mathbf{1}$, the intrinsic reactivity centers in this molecule are revealed, and their potential reactivity trends are clarified. Based on these results, we follow the strategy "from gas phase to condensed phase" to explore and examine the analogous reactions of 1 in solution. Further solution phase experiments reveal that Compound $\mathbf{1}$ undergoes two analogous reactions in mild acidic solution: the acid-catalyzed cyclodehydration reaction and the acid-catalyzed Smiles rearrangement reaction. In addition, the base-catalyzed Smiles rearrangement of $\mathbf{1}$ was observed under moder- ately basic conditions. The gas-phase reactions of 2 and 3 are examined to support the proposed mechanisms in the gas-phase reactions of Compound 1. Herein, the association and difference between the gas-phase reaction mechanisms and their solution phase analogs are discussed and pointed out.

\section{Experimental}

\section{Materials and Reagents}

Compounds 1-8 were synthesized and verified by NMR, IR, and MS. DHB was purchased from Sigma Aldrich Co., St. Louis, MO.

\section{MALDI-SORI-CID Experiments}

The MS/MS experiments were performed using a Fourier transform ion cyclotron resonance mass spectrometer (Ionspec, Irvine, CA) equipped with a $4.7 \mathrm{~T}$ actively shielded super-conducting electromagnet (Cryomagnetics, Oak Ridge, TN) by sustained offresonance irradiation collision-induced dissociation (SORI-CID) [21, 22]. The MALDI source used an ND:YAG laser (355 nm, New Wave, Fremont, CA). The mass isolation window was set as $0.8 \mathrm{~m} / \mathrm{s}$ to eliminate unwanted ions and the off-resonance irradiation frequency was set to $800 \mathrm{~Hz}$; the amplitude of the SORI pulse was the adjustable parameter used to control the degree of fragmentation ranging from 0.8 to $1.8 \mathrm{~V}_{b-p}$ with $\mathrm{N}_{2}$ as collision gas. 


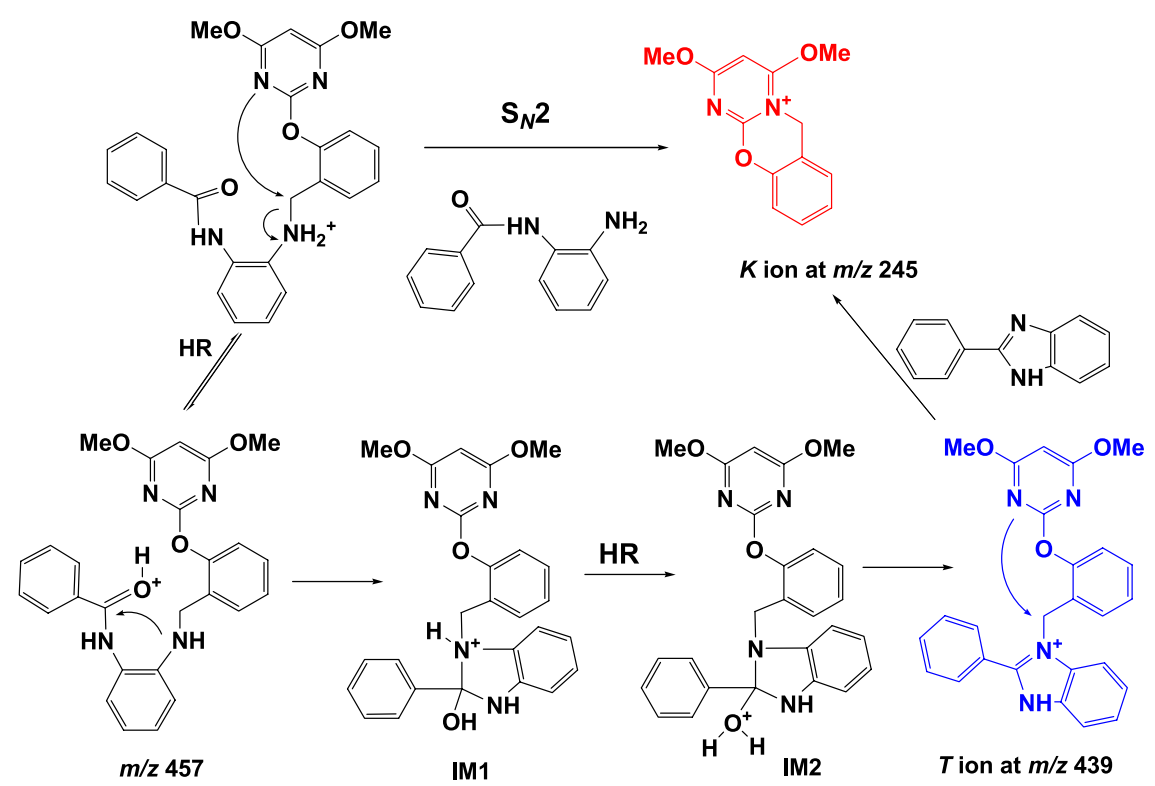

Scheme 2. Proposed dissociation pathways of protonated 1 in SORI-CID.

\section{ESI In-Source CID Experiments}

The ESI in-source CID experiments are performed with a quadrupole mass spectrometer (Agilent Technologies, Palo Alto, CA) [23]. The capillary voltage was set to $-3600 \mathrm{~V}$ for positive ion mode and $+4000 \mathrm{~V}$ for negative ion mode. The nebulizing gas flow rate and curtain gas pressure were $10 \mathrm{ml} / \mathrm{min}$ and $35 \mathrm{psi}$. The fragmentation voltage was set as $150-250 \mathrm{~V}$ to give suitable energy for dissociation.

\section{Computational Methods}

All theoretical calculations were carried out by the semiempirical PM3 method with Spartan molecular modeling software. The structures of ion species on the potential energy surface of the gas-phase reactions are optimized by semiempirical PM3 without imposing any constraints, and the heats of formation of the optimized structures were calculated. All optimized structures were subjected to vibrational frequency analysis [24, 25]. The optimized structures were shown by software Gauss View (version 3.07, Gaussian Inc, Pittsburgh, PA).

\section{Results and Discussion}

\section{Gas Phase Reactions of Protonated 1 and Related Compounds}

Based on our previous report, protonated 1 contains two product ions: the $K$ ion at $\mathrm{m} / \mathrm{z} 245$ and the $T$ ion at $m / z 439$ [17]. The mechanisms for the formation pathways of the $K$ ion at $m / z 245$ and the $T$ ion at $m / z 439$ are shown in Scheme 2; theoretical calculations and additional experiments will be performed to support the proposed mechanisms.

Generation of the $K$ series ions is the most character- istic fragmentation pathway for protonated 2-pyrimidinyloxy- $N$-arylbenzyl amine derivatives. A benzyl migration reaction with intramolecular $\mathrm{S}_{N} 2$ mechanism was proposed to explain this process $[17,26,27]$. Since the solvation effect and hydrogen bond effect does not affect gas-phase reactions, the intrinsic nucleophilicity of the tertiary amine of pyrimidine facilitated such $\mathrm{S}_{N} 2$ reaction. Herein, theoretical computations are invoked to confirm the rationality of this process. Protonated 1 (the protonation location is arylbenzylamine) is used as a model to explain the formation process of the $K$ ion at $\mathrm{m} / \mathrm{z} 245$ with a neutral loss of (2-aminophenyl)(phenyl) methanone (simplified to " $\mathrm{A}$ "). The optimized structures of ion species are shown in Figure 1 and the schematic potential energy surface for this intramolecular $S_{N} 2$ reaction is shown in Figure 2. The energy barrier for the intramolecular $\mathrm{S}_{N} 2$ reaction path is 38.8 $\mathrm{kcal} / \mathrm{mol}$ and the relative energy of the products is 2.2 $\mathrm{kcal} / \mathrm{mol}$. The angle of the N-C-N in the structure of the $\mathrm{S}_{N} 2$ transition-state is $160.4^{\circ}$, which is consistent with the typical $S_{N} 2$ reaction model.

When the benzamide moiety is protonated, the cyclodehydration of protonated 1 induces the gas-phase benzoimidazole-forming reaction and gives rise to the $T$ ion at $m / z$ 439. Theoretical calculations reveal that the gas-phase cyclodehydration reaction involves three steps. First, the neutral arylbenzylamine acts as a nucleophile to attack the protonated carbonyl of amide to form the intermediate 1 (IM1) via a nucleophilic addition transition-state (TS1). Then the proton transfers from the amine to the hydroxyl group to form the intermediate 2 (IM2) via a proton migration transitionstate (TS2). In the last step, the dehydration of IM2 generates the $T$ ion at $\mathrm{m} / \mathrm{z} 439$ with the benzoimidazole moiety via a dehydration transition-state (TS3). The structures of ion species on the potential energy surface 


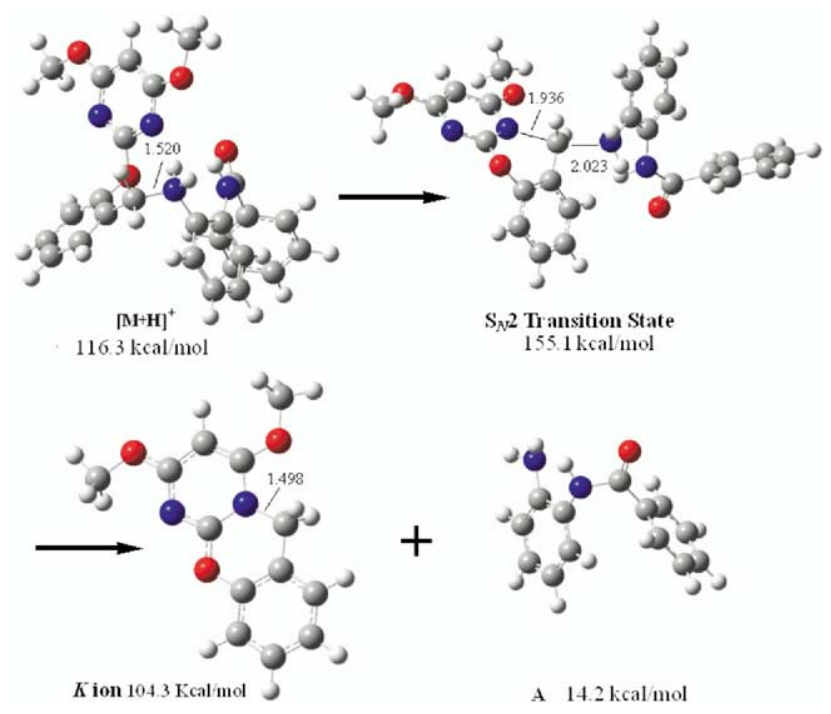

Figure 1. Semi-empirical PM3 optimized structures of the ion species along the gas-phase benzyl migration reaction of protonated 1 (the benzylamine is protonated). The mechanism is proposed to be an intramolecular $S_{N} 2$ reaction. Heats of formation are given in $\mathrm{kcal} / \mathrm{mol}$ and the lengths of the chemical bonds are given in $\AA$.

of this gas-phase cyclodehydration reaction are shown in Figure 3 and the schematic potential energy surface is shown in Figure 4 . The relative energy of the cyclodehydration reaction products is $-6.1 \mathrm{kcal} / \mathrm{mol}$, which demonstrates that this gas-phase cyclodehydration reaction is thermodynamically favorable.

An $S_{N} 1$ mechanism might also be used to explain the formation process of the ion at $\mathrm{m} / \mathrm{z} 245$, and a direct dehydration from protonated amide might also be used to explain the formation process of the ion at $\mathrm{m} / \mathrm{z} 439$. The corresponding mechanisms involved are proposed and shown in Scheme 3. According to this mechanism, the " $K$ ion" at $m / z 245$ has an open-ring structure (ORK ion) and the " $T$ ion" at $m / z 439$ has an open-ring structure (ORT ion). The calculated heat of formation

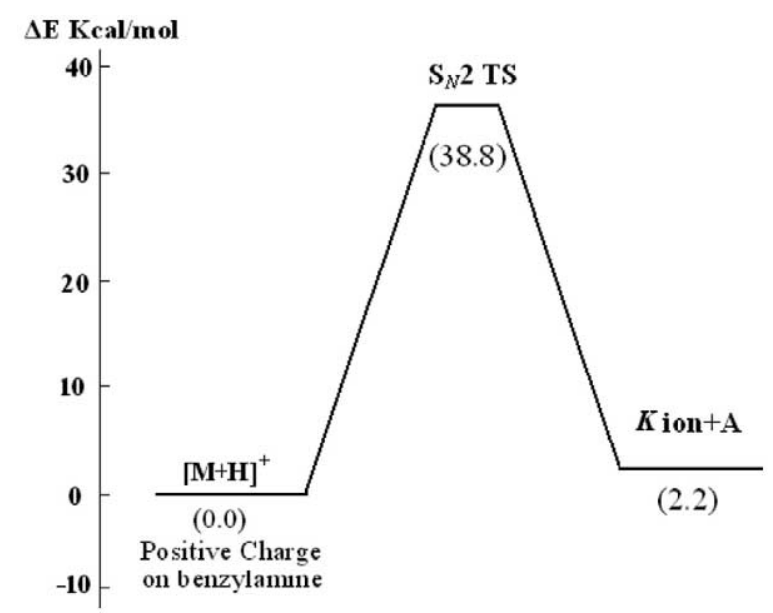

Figure 2. The schematic potential energy surface for the gasphase benzyl migration reaction.
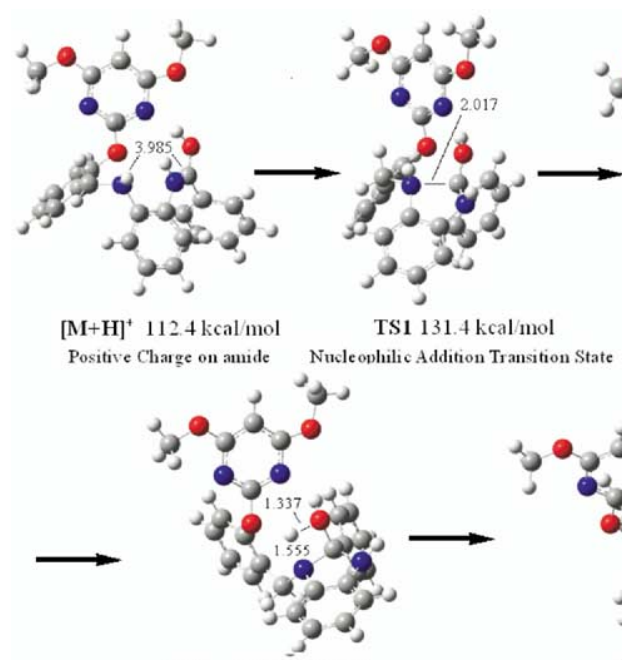

TS2 $145.0 \mathrm{Kcal} / \mathrm{mol}$ Proton transfer Transition State

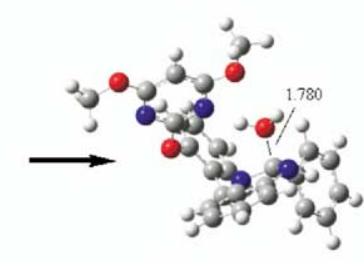

TS3 $125.3 \mathrm{Kcal} / \mathrm{mol}$

Dehydration Transition State

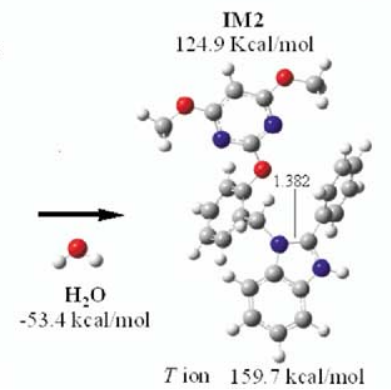

Figure 3. Semi-empirical PM3 optimized structures of the ion species along the gas-phase cyclodehydration reaction pathway of protonated $\mathbf{1}$ (the amide is protonated).

for the optimized structure of the ORK ion is 146.8 $\mathrm{kcal} / \mathrm{mol}$, which is much higher than that of the $K$ ion with the closed-ring structure $(104.3 \mathrm{kcal} / \mathrm{mol})$. Therefore, the $K$ ion with the closed-ring structure is much more stable than the ORK ion and the corresponding benzyl migration pathway is more favorable. The calculated heat of formation for the ORT ion is 192.7 $\mathrm{kcal} / \mathrm{mol}$, which is higher than that of the closed-ring structure ion $(159.7 \mathrm{kcal} / \mathrm{mol})$. Therefore, the $T$ ion with the closed-ring structure ion is much more stable than the ORT ion and the corresponding cyclodehydration pathway is more reasonable.

Theoretical computations show that the energy barrier for the gas-phase cyclodehydration reaction is

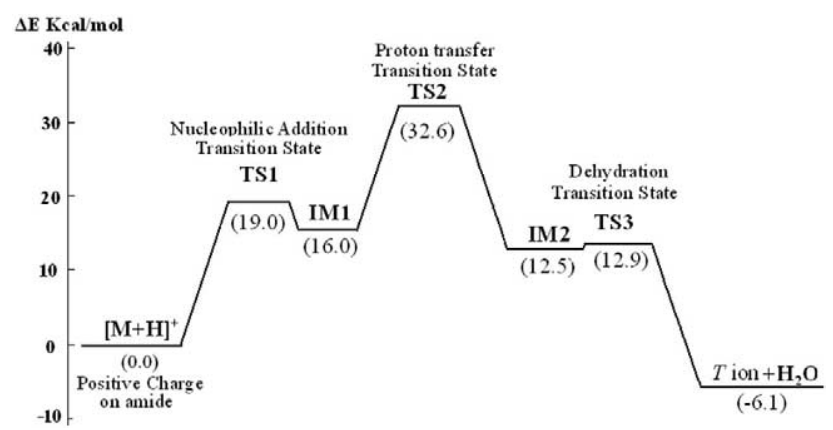

Figure 4. The schematic potential energy surface for the gasphase cyclodehydration reaction. 


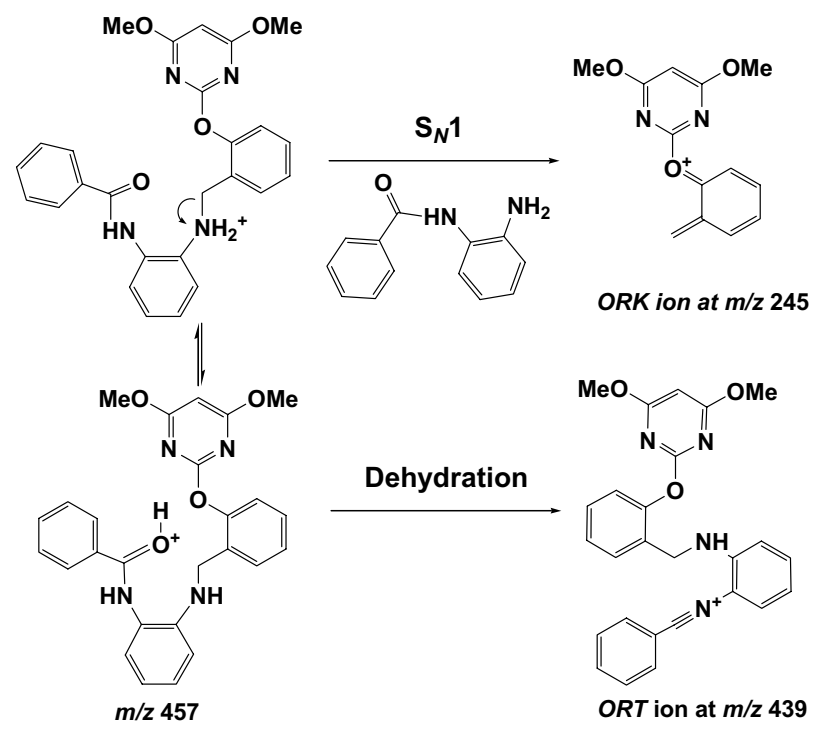

Scheme 3. The proposed mechanisms for the formation of the ORK ion and the ORT ion.

lower than the benzyl migration reaction. The results can be used to explain the reason why the relative abundance of the ion at $\mathrm{m} / \mathrm{z} 439$ is higher than that of the ion at $m / z 245$. Alkali metal cationization has been also explored as an alternative to protonation by changing the site of charge localization and to promote different fragmentation processes. However, alkali metal $\left(\mathrm{Li}^{+}\right.$, $\mathrm{Na}^{+}$, and $\mathrm{K}^{+}$) adduct ions of $\mathbf{1}$ do not yield informative fragment ions. Thus, it is concluded that a proton is important to trigger the reactions in the gas-phase and this clue suggests that this compound might undergo analogous reactions under acid-catalyzed conditions.

Similarly, the SORI-CID spectrum of protonated 4, shown in Figure $5 a$, gives the $K$ ion at $m / z 263$ and the $T$ ion at $m / z 491$. Compound 4 has the fluorine and chlorine substituents in the molecule. Thus, these sub-

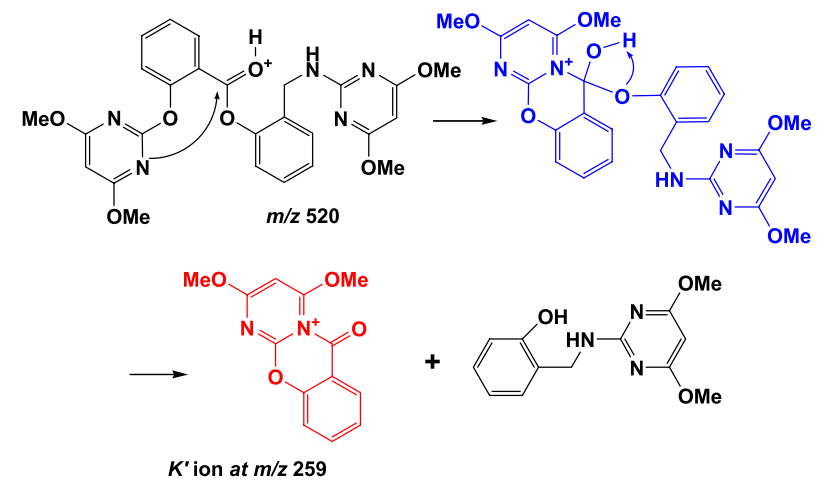

Scheme 4. Proposed dissociation pathways of protonated 5 in SORI-CID.

stituents can be regarded as markers to support the dissociation process. The SORI-CID spectrum of protonated 5, shown in Figure 5b, contains only one product ion at $\mathrm{m} / \mathrm{z} 259$. An acyl migration reaction is proposed to explain the formation process of the product ion at $m / z 259$, and the corresponding mechanism is shown in Scheme 4. The ion at $\mathrm{m} / \mathrm{z} 259$ has a cyclic amide structure, which is similar to that of the $K$ ion, so herein it is called a $K^{\prime}$ ion. This acyl migration reaction can be regarded as additional proof for the intrinsic nucleophilicity of the tertiary amine of pyrimidine in the gas-phase reaction. The mechanisms of gas-phase benzyl migration and acyl migration reactions are similar to the mechanism of the "histidine effect", which refer to the nucleophilic attack of the imidazole nitrogen of the histidine side-chain to the protonated amide bond to form the cyclic (non-oxazolone derivative) C-terminal fragments $[28,29]$. The computation for the acyl migration reaction, the accurate mass determination results and the X-ray crystal data of 2 and 3 can be seen in the Supplementary Material section in the online version of this article.
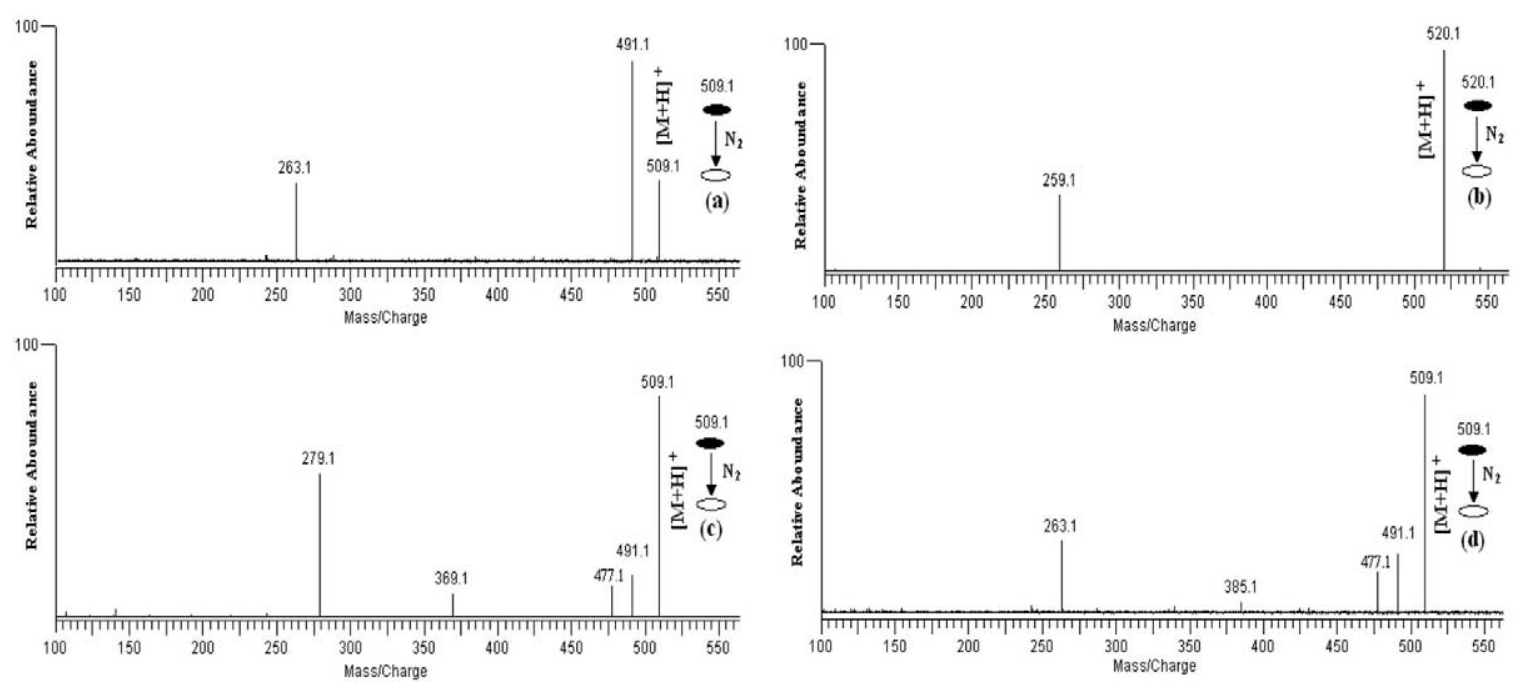

Figure 5. The positive ion SORI-CID spectra of protonated 4, 5, 6, and 7: (a) protonated 4 at $m / z$ 509; (b) protonated 5 at $\mathrm{m} / \mathrm{z}$ 520; (c) protonated 6 at $\mathrm{m} / \mathrm{z} 509$; (d) protonated 7 at $\mathrm{m} / \mathrm{z} 509$. 
258

WANG ET AL.

J Am Soc Mass Spectrom 2006, 17, 253-263

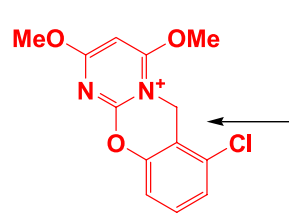

$m / z 279$

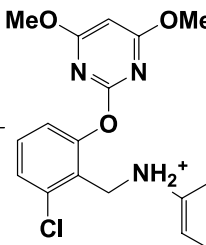

$m / z 509$

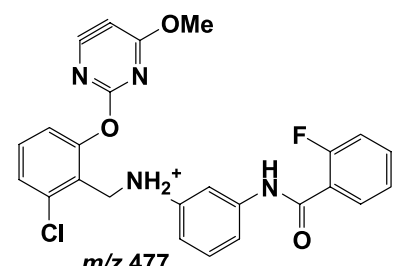

$m / z 477$
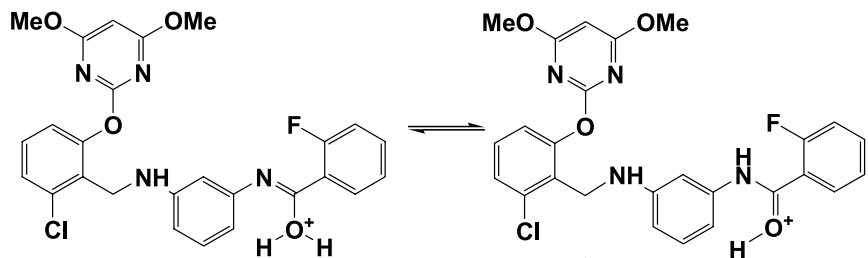

Dehydration
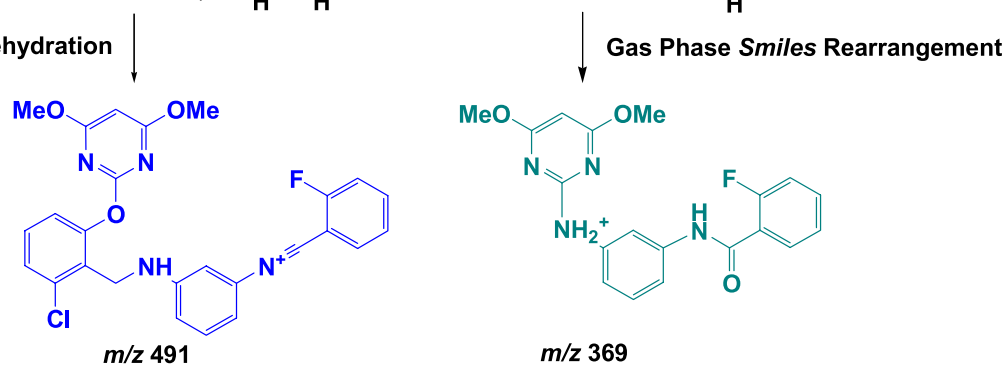

$\mathrm{MeO}$<smiles>COc1cc(I)nc(N)n1</smiles>

$m / z 369$

Scheme 5. Proposed dissociation pathways of protonated 6 in SORI-CID.

The aminoacyl group in 6 and 7 is at a meta-position and para-position, respectively. Therefore, 6 and 7 are

protonated 2-pyrimidinyloxy- $N$-arylbenzyl amine derivatives. The SORI-CID spectrum of protonated 6 is used to examine substituent effects in the reactions of shown in Figure sc, and the proposed dissociation

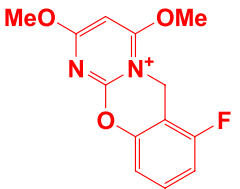

$m / z 263$
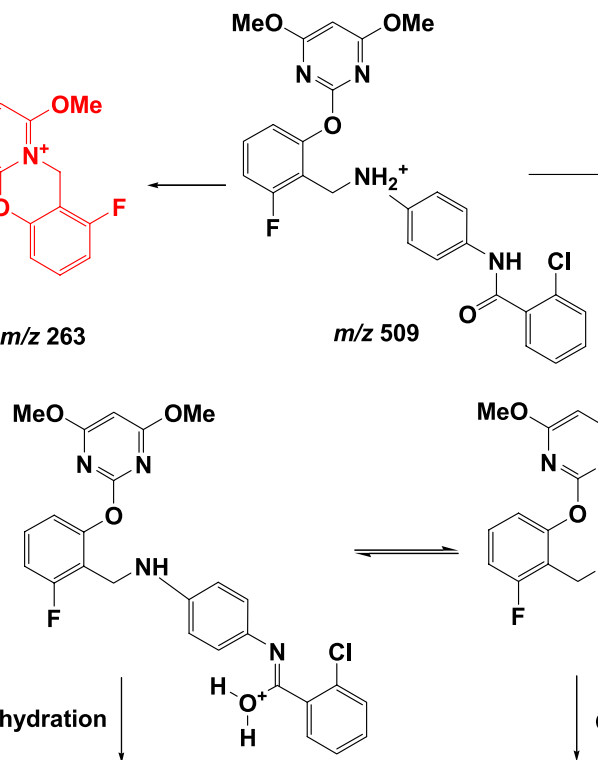

$\mathrm{MeO}$

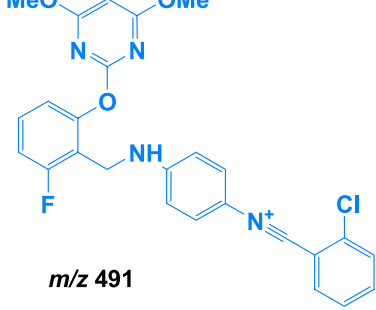

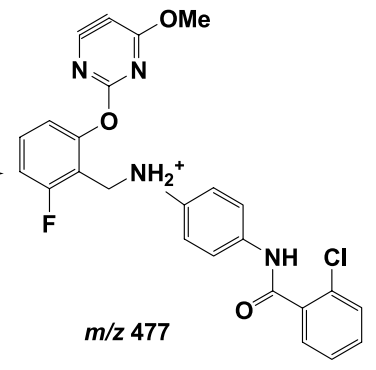
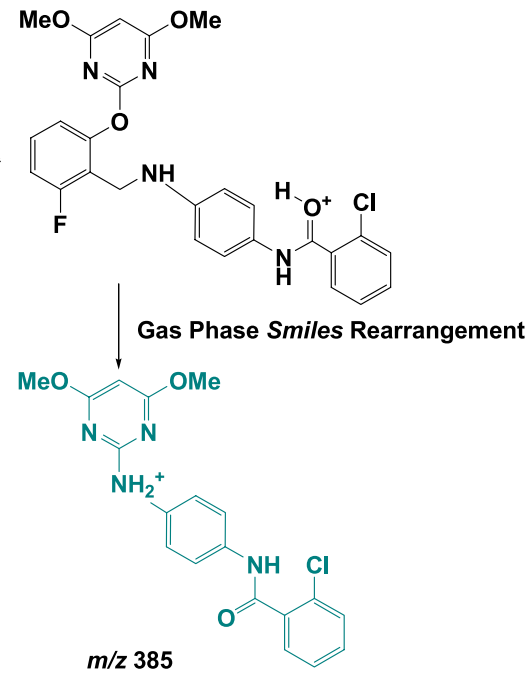

Scheme 6. Proposed dissociation pathways of protonated 7 in SORI-CID. 

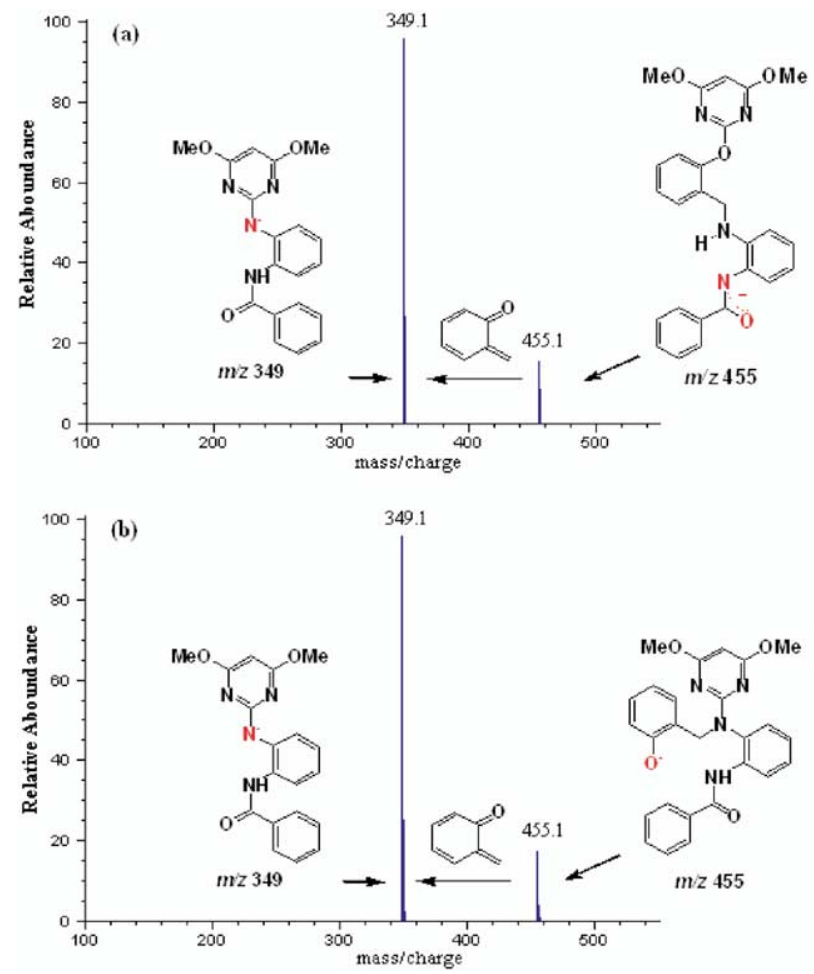

Figure 6. The negative ion in-source CID spectra of deprotonated 1 and 3, (a) deprotonated 1; (b) deprotonated 3.

pathways are shown in Scheme 5. The SORI-CID spectrum of protonated 7 is shown in Figure $5 d$, and the proposed dissociation pathways are shown in and Scheme 6. There are two notable changes in the dissociation pattern when the aminoacyl group does not locate in the ortho-position. First, the protonated 6 and 7 undergo the Smiles rearrangement when a proton migrates from arylbenzylamine to the aminoacyl group. Second, the protonated 6 and 7 dehydrate via a gasphase retro-Ritter mechanism [30, 31]; therefore, the extent of the dehydration of protonated 6 and protonated 7 is a minor process compared with that of protonated 1 .

\section{Gas Phase Reactions of Deprotonated 1 and Related Compounds}

The conjugative effect of two neighboring aromatic rings makes the enolization of amide group of Compound 1 more favorable. The enol form of 1 with an active hydroxyl group can be ionized with ESI in the negative ion mode [32]. The in-source CID mass spectrum of deprotonated 1 is shown in Figure 6a. The formation process of the ion at $\mathrm{m} / \mathrm{z} 349$ from deprotonated 1 cannot be rationalized without invoking a skeletal rearrangement before the fragmentation. A gas-phase anionic type Smiles rearrangement mechanism is proposed to explain the formation of the ion at $\mathrm{m} / \mathrm{z}$ 349. The mechanism is shown in Scheme $7[33,34]$. The in-source CID spectrum of deprotonated 3 is shown in Figure 6b. Interestingly, the structure of deprotonated 3 is the same as the structure of the $R E$ ion (mentioned in Scheme 7) and in-source CID of deprotonated 3 gives the same product ion at $m / z 349$, which offers convincing evidence for the anionic type gasphase Smiles rearrangement mechanism of deprotonated 1.

The Smiles rearrangement reaction is known mainly through a base-catalyzed rearrangement mechanism, which involves a Meisenheimer complex [33-38]. The goal of our calculations for this interesting gas-phase anionic type Smiles rearrangement is to show the possible existence of some transition states and reaction intermediates and their relative energies. Firstly, the proton migrates from benzylamine to the enol anion to give the benzylnitrogen anion, which attacks the 2-position carbon of pyrimidine as the nucleophile to form the Meisenheimer complex via an aromatic nucleophilic
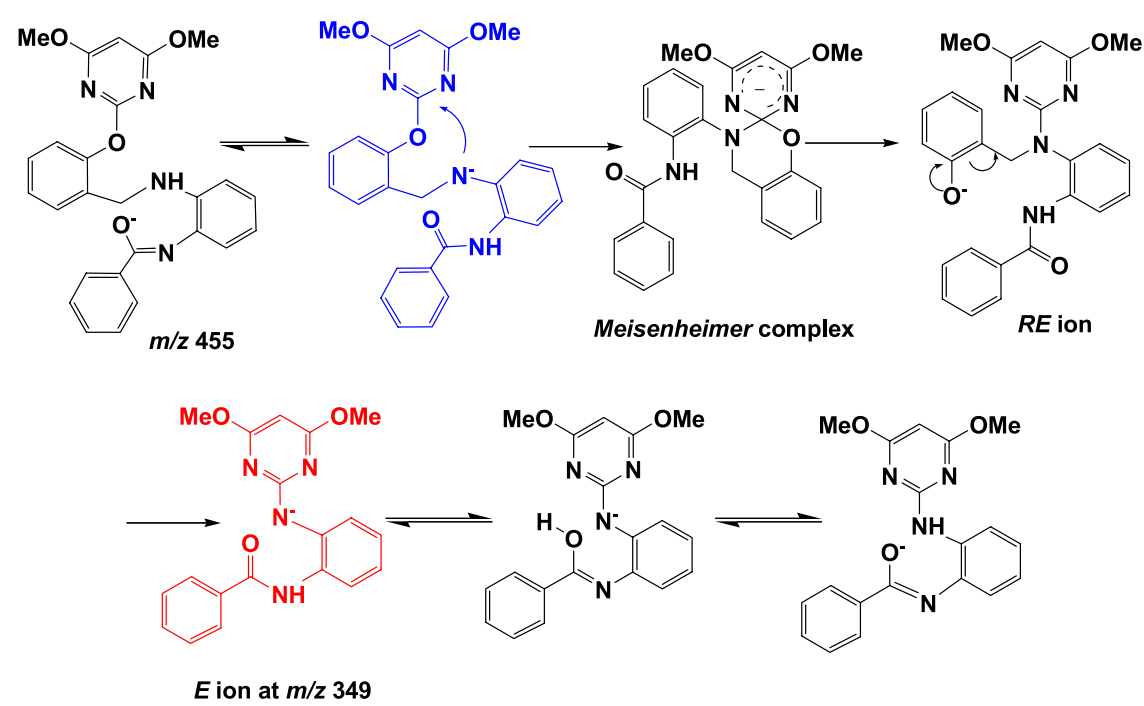

Scheme 7. Proposed formation pathway of the ion at $m / z 349$ from in-source CID of deprotonated 1. 


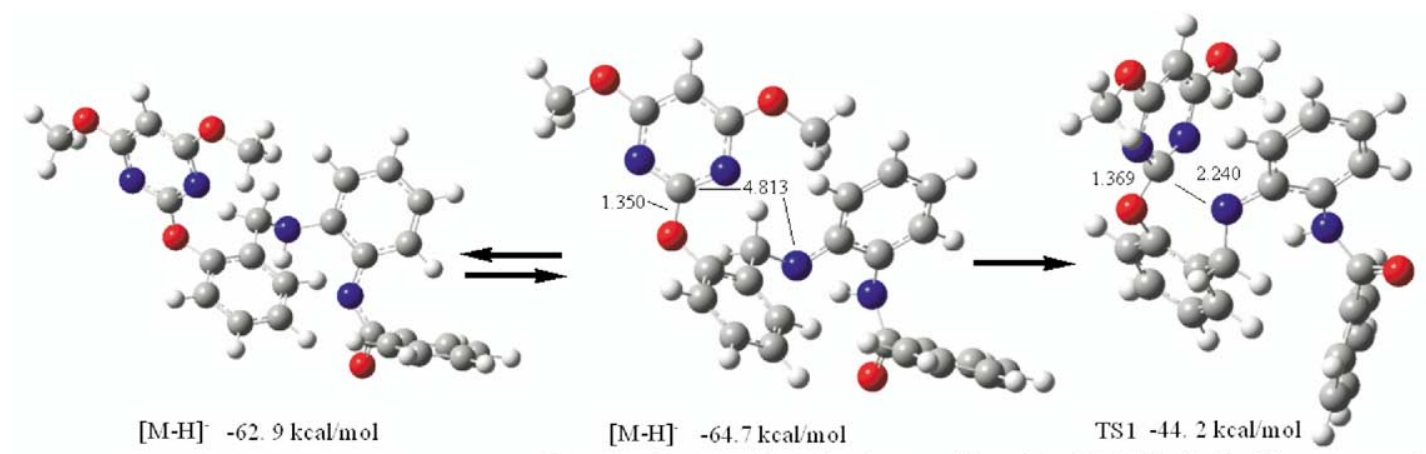

Negative charge on amide

Negative charge on benzylamine

Transition State 1 in Similes Rearrangement
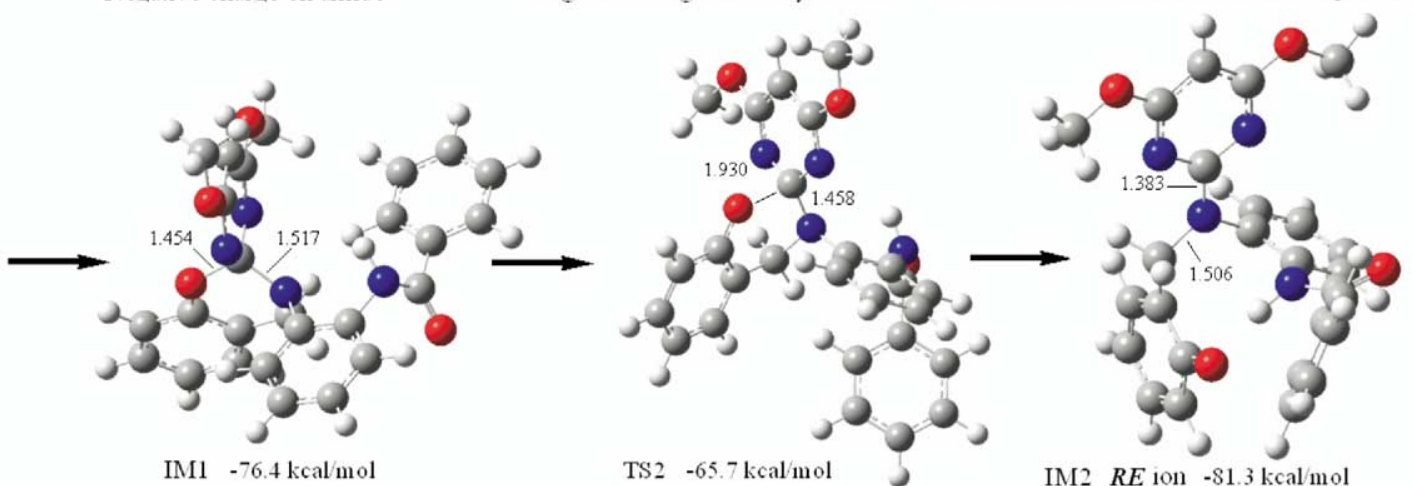

IMl $\quad-76.4 \mathrm{kcal} / \mathrm{mol}$

TS2 $-65.7 \mathrm{kcal} / \mathrm{mol}$

J

IM2 $R E$ ion $-81.3 \mathrm{kcal} / \mathrm{mol}$

Meisenheimer Complex Intermediate Transition State 2 in Smiles Rearrangement Similes Rearrangement Product Ion

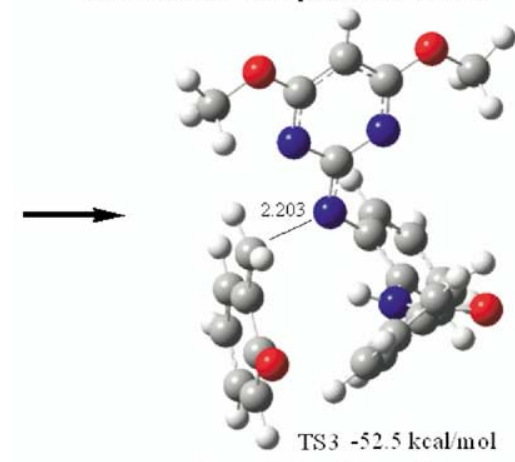

Retro-Michael Transition State

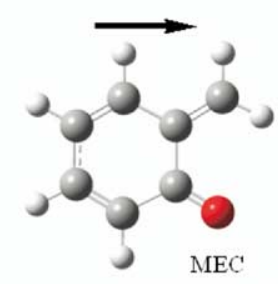

$11.7 \mathrm{kcal} / \mathrm{mol}$

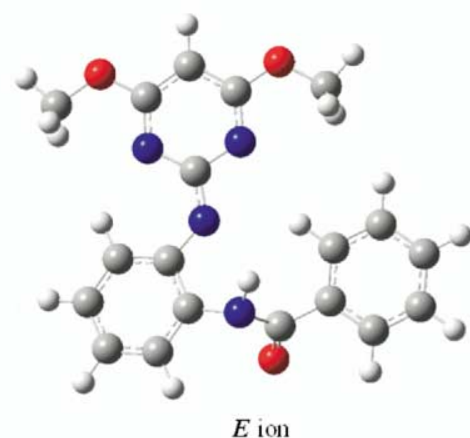

$-69.4 \mathrm{kcal} / \mathrm{mol}$

Figure 7. Semi-empirical PM3 optimized structures of the ion species involved in the formation process of the ion at $\mathrm{m} / \mathrm{z} 349$ from deprotonated 1 . The deprotonated 1 undergoes gas-phase Smiles rearrangement to $R E$ ion via Meisenheimer complex and then dissociate to the ion at $\mathrm{m} / \mathrm{z} 349$.

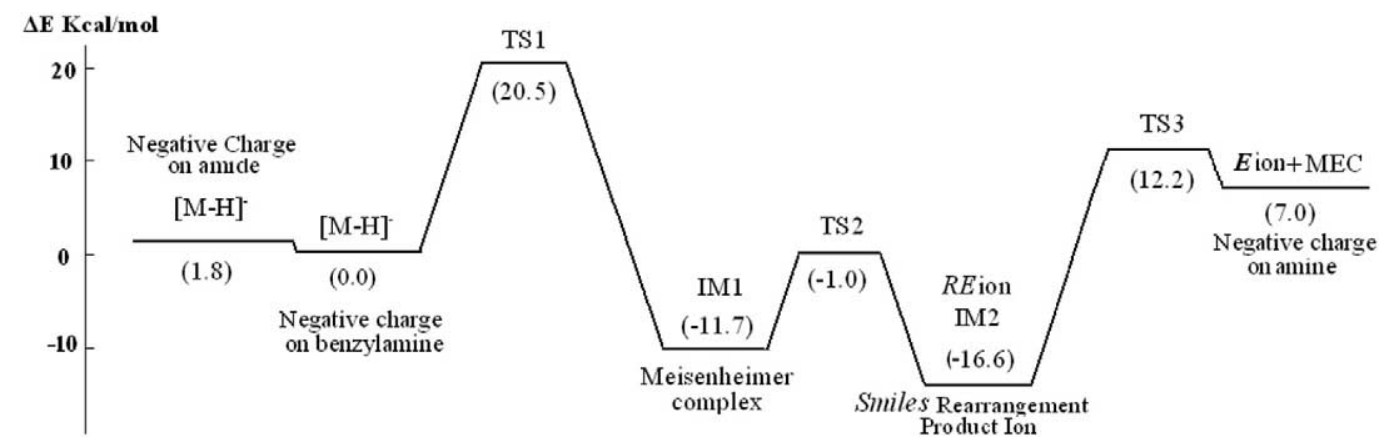

Figure 8. The schematic potential energy surface for the fragmentation pathway of deprotonated 1. 


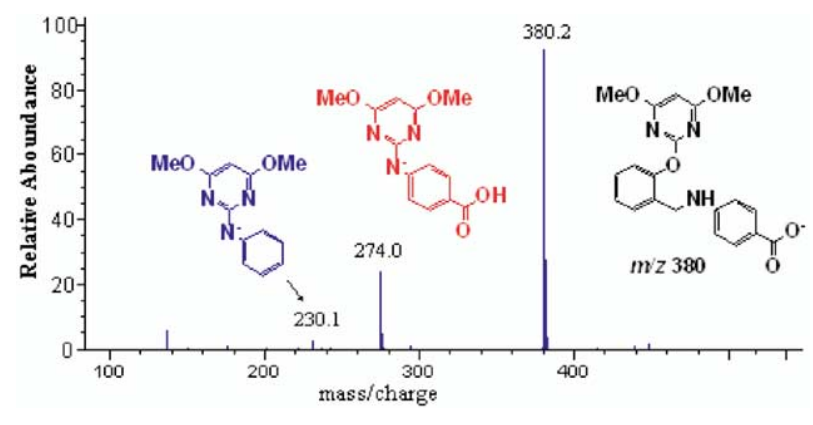

Figure 9. The in-source CID spectrum of deprotonated 8 .

addition transition-state (TS1). Secondly, the cleavage of the $\mathrm{C}-\mathrm{O}$ bond in the Meisenheimer complex gives rise to the $R E$ ion via an elimination transition-state (TS2) $[39,40]$. Finally, the $R E$ ion fragments into the ion at $\mathrm{m} / \mathrm{z} 349$ with a neutral loss of 6-methylenecyclohexa2,4-dienone (MEC) through a retro-Michael transitionstate (TS3) [19, 40]. The optimized structures of ion species involved in the fragmentation pathway of deprotonated 1 are shown in Figure 7, and the schematic potential energy surface is shown in Figure 8. Analysis in Figure 8 shows that the formation of the Meisenheimer complex and $R E$ ion is favorable thermodynamically.

Compound 8 has a carboxyl group and can be easily ionized with ESI in the negative ion mode. The insource CID spectrum of deprotonated 8 contains the product ions at $m / z 274$ and $m / z 230$, which is shown in Figure 9. Analysis in Figure 9 shows that deprotonated 8 also undergoes a gas-phase Smiles rearrangement and then dissociates to the ion at $\mathrm{m} / \mathrm{z} 274$ and further to the ion at $\mathrm{m} / \mathrm{z} 230$ by loss of $\mathrm{CO}_{2}$.

\section{Predicting Chemical Transformations of Compound 1 in Solution}

Previous studies have demonstrated that it is possible to correlate the behavior of the reactions of closed-shell organic ions in the gas phase and in solution [9-12]. The study of gas-phase reactions of protonated and deprotonated 1 allows us to investigate intramolecular organic reactions of these ion species under solvent-free conditions. These tandem mass spectrometric results provide information about the intrinsic intramolecular chemical reactivities of this compound, which include the aromatic substitution of the C-2 position of pyrimidine with nucleophiles and the condensation of aminoacyl group with ortho-position benzylamine. Our strategy "from gas phase to condensed phase" means to collect and summarize the chemical information of the compound in the mass spectrometric process to provide valuable clues of possible chemically analogous transformations or reactions of the compound in solution. Since the gas-phase CID reactions of 1 occur under protonation or deprotonation conditions, further experiments in solution are performed to explore the analogous reactions of $\mathbf{1}$ under acidic or base-catalyzed conditions.

\section{Analogous Reactions of Compound $\mathbf{1}$ in Solution}

Investigation of the chemical transformations of $\mathbf{1}$ in the solution phase began under strong acidic and basic conditions, which seems unfavorable because of complicated degradation reactions. When 1 reacted in a mild acidic solution (acetic acid:acetone, 1:1) at $25^{\circ} \mathrm{C}$ with agitation, Compounds 2 and 3 were obtained as final products $(2: 3,74.2 \%: 21.7 \%$, detected by

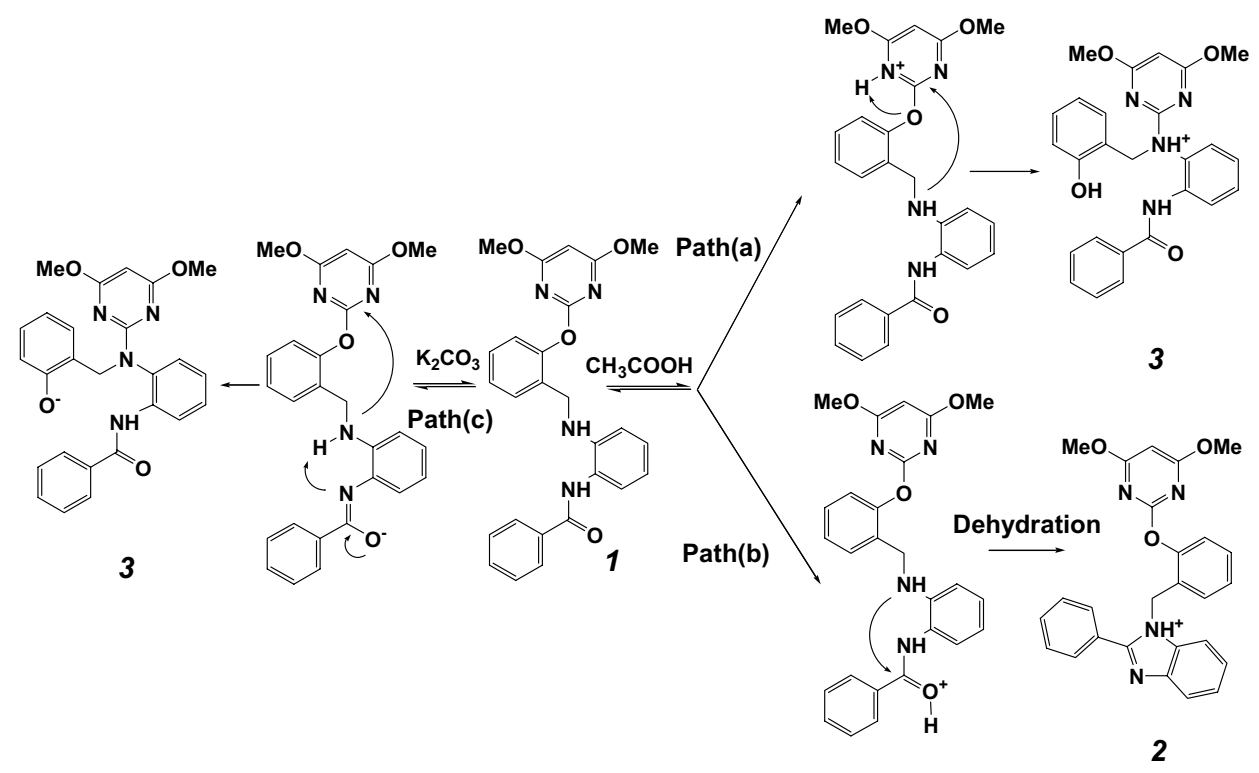

Scheme 8. Proposed mechanisms of the two competitive acid-catalyzed transformation pathways and the base-catalyzed transformation pathway of 1 in solution. 


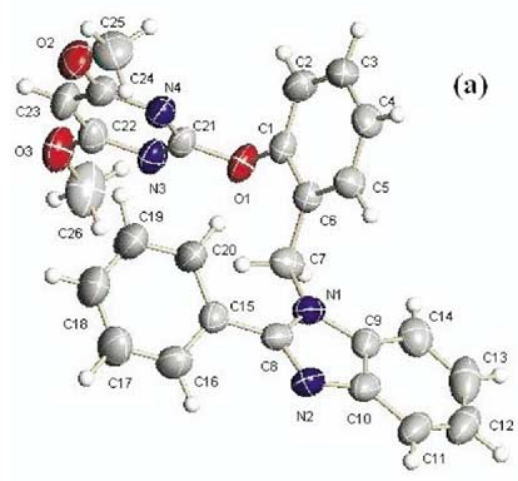

Compound 2

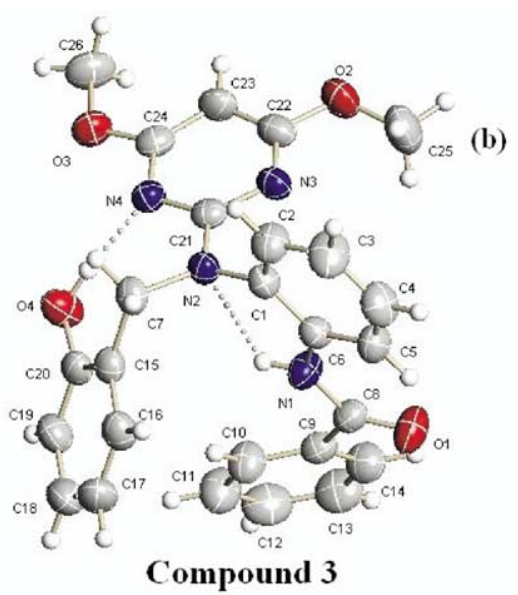

Figure 10. The X-ray crystal structures of 2 and 3: (a) Compound 2; (b) Compound 3.

HPLC-MS). The mechanisms of two competitive reactions are shown in Scheme 8. Path $\mathbf{a}$ is proposed to be an acid-catalyzed Smiles rearrangement reaction. In this reaction pathway, the pyrimidine ring is activated by protonation towards the nucleophiles under acidic conditions, since the protonation of the vicinal nitrogen in pyrimidine withdraws electrons from the C-2 position $[20,38]$. Path $\mathbf{b}$ is an acid-catalyzed cyclodehydration process [41, 42], and the mechanism is similar to that of its gas-phase analogous reaction; such cyclodehydration strategy has been reported as a convenient route to synthesize benzimidazoles [42].

It is proposed that the failure to observe the analogous reactions of the gas-phase benzyl migration reaction in solution is caused by solvent effects or protonation on the nitrogen in the pyrimidine ring. The protonation effect and the hydrogen bond interaction effect withdraw electrons from the nitrogen in the pyrimidine, which decreases the nucleophilicity of the nitrogen of pyrimidine in solution. Therefore, such an intramolecular $\mathrm{S}_{N} 2$ reaction was not observed in solution.

In a mild basic solution (saturated $\mathrm{K}_{2} \mathrm{CO}_{3}$ solution, methanol:acetone, $1: 1)$ at $25^{\circ} \mathrm{C}$ with agitation for two days, 1 rearranged to 3 . Path $\mathbf{c}$ is a base-catalyzed Smiles rearrangement reaction and the mechanism is also shown in Scheme $8[36,37]$. The transformation process of $\mathbf{1}$ in basic solution is similar to the dissociation pathway of deprotonated 1 in the gas-phase.

Fortunately, the single crystal X-ray structures of 2 and 3 were obtained and shown in Figure 10. As a result, the predictions based on experimental results of tandem mass spectrometry are confirmed by the experiments in solution, which show that the solution-phase reactions and the gas-phase analogs occur via the same "real reactive ion species".

\section{Conclusions}

The present study reports a significant association between gas-phase reactions and the analogous reactions of 1 in solution. The CID cyclodehydration of protonated 1 into the corresponding protonated 2 appears to proceed in a fashion similar to the corresponding process induced by acid-catalyzed conditions in solution. The CID anionic type Smiles reaction of deprotonated 1 into deprotonated 3 also has its solution phase counterpart: the base-catalyzed Smiles rearrangement. Based on the above information, the gas-phase reactions of 1 and its solution phase transformation pathways are clarified. Overall, the tandem mass spectrometric results provide valuable clues and insights for their solution reactions. As a high-throughput and green chemistry method, without consuming large amounts of organic solvents, using tandem mass spectrometry to predict the chemical transformations of drugs and pesticides in solution will become a promising technique in degradation studies for drugs and pesticides.

\section{Acknowledgments}

The authors thank the National Natural Science Foundation of China (no.20475059), major state basic research development program (no.2003CB114406), and the Chinese Academy of Sciences (KGCX2-SW-213-04) for financial support.

\section{References}

1. Farran, A.; Ruiz, S. Application of Solid-Phase Extraction and Micellar Electrokinetic Capillary Chromatography to the Study of Hydrolytic and Photolytic Degradation of Phenoxy Acid and Phenylurea Herbicides. J. Chromatogr. A. 2004, 1024, 267-274.

2. Corcia, A. D.; Costantino, A.; Crescenzi, C.; Samperi. R. Quantification of Phenylurea Herbicides and Their Free and Humic Acid-Associated Metabolites in Natural Waters. J. Chromatogr. A. 1999, 852, 465-474.

3. Sabika, H.; Jeannot, R.; Rondeau, B. Multiresidue Methods Using Solid-phase Extraction Techniques for Monitoring Priority Pesticides, Including Triazines and Degradation Products, in Ground and Surface Waters. J. Chromatogr. A. 2000, 885, 217-236.

4. Bertrand, C.; Witczak-Legrand, A.; Sabadie, J.; Cooper, J. F. Alcoholysis, Chemical Hydrolysis, and Degradation on Various Minerals. J. Agric. Food Chem. 2003, 51, 7717-7721.

5. Lin, C. H; Lerch, R. N.; Garrett, H. E.; George, M. F. Degradation of Isoxaflutole (Balance) Herbicide by Hypochlorite in Tap Water. J. Agric. Food Chem. 2003, 51, 8011-8014.

6. Vincze, A.; Yinon, J. Tandem Mass Spectrometric Collision-Induced Dissociation Study of in s-Triazines an Ion Trap Mass Spectrometer. J. Mass Spectrom. 1997, 32, 1320-1331.

7. Budde, W. L. Analytical Mass Spectrometry of Herbicides. Mass Spectrom. Rev. 2004, 23, 1-24. 
8. Pico, Y.; Blasco, C.; Font, G. Environmental and Food Applications of LC-Tandem Mass Spectrometry in Pesticide-Residue Analysis: An Overview. Mass Spectrom. Rev. 2004, 23, 45-85.

9. Glish, G. L, Cooks, R. G. The Fischer Indole Synthesis and Pinacol Rearrangement in the Mass Spectrometer. J. Am. Chem. Soc. 1978, 100, $6720-6725$

10. Lobodin, V. V.; Ovcharenko, V. V. Pihlaja, K.; Morzherin, Y. Y. Lebedev, A. T. "Tert-Amino Effect" Induced by Electron Ionization and Comparison with Thermal Reaction in Solution. Rapid Commun. Mass Spectrom. 2004, 18, 724-728

11. Bowie, J. H. Twenty-Five Years of Negative Ion Studies at Adelaide. Org. Mass Spectrom. 1993, 28, 1407-1413.

12. Eichinger, P. C. H.; Dua, S. Bowie, J. H. A Comparison of Skeletal Rearrangement Reactions of Even-Electron Anions in Solution and in the Gas Phase. Int. J. Mass Spectrom. 1994, 133, 1-12.

13. Chen, H.; Chen, H. W.; Cooks, R. G.; Bagheri, H. Generation of Arylnitrenium Ions by Nitro-Reduction and Gas-Phase Synthesis of $N$-Heterocycles. J. Am. Soc. Mass Spectrom. 2004, 15, 1675-1688.

14. Mcluckey, S. A.; Glish, G. L.; Busch, K. L. Mass Spectrometry/Mass Spectrometry: Techniques and Applications of Tandem Mass Spectrometry; VCH Publishers, Inc.: New York, 1988; pp 173-277.

15. Porter, C. J.; Beynon, J. H.; Ast, T. The Modern Mass Spectrometer-A Complete Chemical Laboratory. Org. Mass Spectrom. 1981, 16, 101-114.

16. Patents for 2-pyrimidinyloxy- $N$-arylbenzyl amine derivatives: (a) Lu, L. Chen, J., Cai, X., Li, M. Z., Wu, Y., Wang, Y. H. China Patent, CN 1323788-A, 2001; Chem. Abstr. 2002, 137, 74803. (b) Lu, L.; Chen, J.; Wu, J.; Ling, W.; Mao, L. S.; Li, M. Z.; Cai, X.; Peng, W. L.; Wu, Y.; Wu, S. G.; Wang, H. J.; Wang, G. C.; Cui, H.; Han, S. D.; Qiu, W. L.; Wang, Y. H. World Patent, WO 200234724-A1, 2002; Chem. Abstr. 2002, 136, 355244.

17. Wang, H. Y.; Guo, Y. L.; Lu, L. Studies of Rearrangement Reactions of Protonated and Lithium Cationized 2-Pyrimidinyloxy- $\mathrm{N}$-Arylbenzylamine Derivatives by MALDI-FT-ICR Mass Spectrometry. J. Am. Soc. Mass Spectrom. 2004, 15, 1820-1832.

18. Wang, H. Y.; Zhang, X.; Guo, Y. L.; Tang, Q. H.; Lu, L. Sulfonamide Bond Cleavage in Benzenesulfonamides and Rearrangement of the Resulting $p$-Aminophenylsulfonyl Cations: Application to a 2-Pyrimidinyl-Oxybenzyl-Aminobenzenesulfon Amide Herbicide. Rapid Commun. Mass Spectrom. 2005, 19, 1696-1702.

19. Wang, H. Y.; Zhang, X.; Guo, Y. L.; Lu, L. Mass Spectrometric Studies of the Gas Phase Retro-Michael Type Fragmentation Reactions of 2-Hydroxybenzyl-N-Pyrimidinylamine Derivatives. J. Am. Soc. Mass Spectrom. 2005, 16, 1561-1573.

20. Wang, H. Y.; Liao, Y. X.; Guo, Y. L.; Tang, Q. H.; Lu, L. Interesting Acid Catalyzed O-N--Type Smiles Rearrangement Reactions of 2-Pyrimidinyloxy-N-Arylbenzylamine Derivatives. Synlett 2005, 8, 1239-1242.

21. Gauthier , J. W.; Trautman, T. R.; Jacobson, D. B. Sustained OffResonance Irradiation for CAD Involving FTMS. CAD Technique that Emulates Infrared Multiphoton Dissociation. Anal. Chim. Acta 1991, 246, 211-225.

22. Marshall, A. G.; Hendrickson, C. L.; Jackson, G. S. Fourier Transform Ion Cyclotron Resonance Mass Spectrometry: A Primer. Mass Spectrom. Rev. 1998, 17, 1-35.

23. Gabelica, V.; Pauw, E. D. Internal Energy and Fragmentation of Ions Produced in Electrospray Sources. Mass Spectrom. Rev. 2005, 24, 566587.

24. PC Spartan Pro, version 1,0,7, Wavefunction Inc., Von Karman, Suite 370, Irvine, CA, Jun. 14, 2001

25. (a) Stewart, J. J. P.; Davis, L. P.; Burggraf, L. W. Semiempirical Calculations of Molecular Trajectories: Method and Applications to Some Simple Molecular Systems. J. Comp. Chem. 1987, 8, 1117-1123; (b) Stewart, J. J. P. Optimization of Parameters for Semiempirical Methods.
I. J. Comp. Chem. 1989, 10, 209-220; (c) Stewart, J. J. P. Optimization of Parameters for Semiempirical Methods. II. J. Comp. Chem. 1989, 10, 221-264.

26. Oin, X. Z. Tandem Mass Spectrum of a Farnesyl Transferase Inhibitor Gas-Phase Rearrangements Involving Imidazole. J. Mass Spectrom. 2001, 36, 911-917.

27. Qin, X. Z. Tandem Mass Spectrum of a Growth Hormone Secretagogue: Amide Bond Cleavage and Resultant Gas-Phase Rearrangement. J. Am. Soc. Mass Spectrom. 2002, 13, 371-377.

28. (a) Wysocki, V. H.; Tsaprailis, G.; Smith, L. L.; Breci, L. A. Mobile and Localized Protons: A Framework for Understanding Peptide Dissociation. J. Mass Spectrom. 2000, 35, 1399-1406; (b) Farrugia, J. M.; Taverner, T.; O'Hair, R. A. J. Side-Chain Involvement in the Fragmentation Reactions of the Protonated Methyl Esters of Histidine and Its Peptides. Int. J. Mass Spectrom. 2001, 209, 99-112.

29. Paizs, B.; Suhai, S. Fragmentation Pathways of Protonated Peptides. Mass Spectrom. Rev. 2005, 24, 508-548.

30. (a) Ritter, J. J.; Minieri, P. P. A New Reaction of Nitriles. I. Amides from Alkenes. J. Am. Chem. Soc. 1948, 70, 4045-4048; (b) Ritter, J. J.; Kalish, J. A New Reaction of Nitriles. II. Synthesis of $t$-Carbinamines. J. Am. Chem. Soc. 1948, 70, 4049-4050.

31. Bulent, B.; Viktorya, A.; Chava, L. Elimination of Water from the Carboxyl Group of GlyGlyH ${ }^{+}$. J. Am. Soc. Mass Spectrom. 2003, 14, 1192-1203.

32. Bowie, J. H. The Fragmentation of Even-Electron Organic Negative Ion. Mass Spectrom. Rev. 1990, 9, 349-379.

33. (a) Eichinger, P. C. H.; Bowie, J. H.; Hayes, R. H. The Gas-Phase Smiles Rearrangement: A Heavy Atom Labeling Study. J. Am. Chem. Soc. 1989, 111, 4224-4227; (b) Eichinger, P. C. H.; Bowie, J. H. The Gas-Phase Smiles Rearrangement. The Effect of Ring Substitution. An Oxygen-18 Labeling Study. Org. Mass Spectrom. 1992, 27, 995-999.

34. Chen, H.; Chen, H. W.; Cooks, R. G. Meisenheimer Complexes Bonded at Carbon and at Oxygen. J. Am. Soc. Mass Spectrom. 2004, 15, 998-1004.

35. Warren, L. A.; Smiles, S. Iso- $\beta$-Naphthol Sulphide. J. Chem. Soc. 1930, $178,956-963$

36. (a) Truce, W. E.; Kreider, E. M.; Brand, W. W. The Smiles and Related Rearrangements of Aromatic Systems. Organic Reaction. Vol. XVIII; Wiley: New York, 1970; pp 99-215; (b) Radl, S. Aromatic Nucleophilic Denitrocyclization Reactions. Advances in Heterocyclic Chemistry. Vol. LXXXIII; Academic: San Diego, 2002; pp 189-257.

37. (a) Kleb, K. G. New Rearrangement of the Smiles Reaction Type. Angew. Chem. Int. Ed. 1968, 7, 291; (b) Selvakumar, N.; Srinivas, D.; Azhagan, A. M. Observation of $O-N$-Type Smiles Rearrangement in Certain Alkyl Aryl Nitro Compounds. Synthesis 2002, 16, 2421-2425.

38. (a) Rodig, O. R.; Collier, R. E.; Schlatzer, R. K. Pyridine Chemistry. I. The Smiles Rearrangement of the 3-Amino-2, 2'-Dipyridyl Sulfide System. J. Org. Chem. 1964, 29, 2652-2658; (b) Shin, J. M.; Cho, Y. M.; Sachs, G. Chemistry of Covalent Inhibition of the Gastric $\left(\mathrm{H}^{+}, \mathrm{K}^{+}\right)$-ATPase by Proton Pump Inhibitors. J. Am. Chem. Soc. 2004, 126, 7800-7811.

39. Peterson, J.; Allikmaa, V.; Subbi, J.; Pehk, T.; Lopp, M.Structural Deviations in Poly(amidoamine) Dendrimers: A MALDI-TOF MS Analysis. Eur. Polymer J. 2003, 39, 33-42.

40. He, M.; McLuckey, S. A. Tandem Mass Spectrometry of Half-Generation PAMAM Dendrimer Anions. Rapid Commun. Mass Spectrom. 2004, 18, 960-972.

41. Grimmett, M. R. Imidazole and Benzimidazole Synthesis; Academic Press: San Diego, 2005; pp 72-76.

42. Fonseca, T.; Gigante, B.; Gilchrist, T. L. A Short Synthesis of Phenanthro[2,3-d]Imidazoles from Dehydroabietic Acid. Application of the Methodology as a Convenient Route to Benzimidazoles. Tetrahedron. 2001, 57, 1793-1799. 